\title{
An Educational Robotics Lab to Investigate Cognitive Strategies and to Foster Learning in an Arts and Humanities Course Degree
}

\author{
https://doi.org/10.3991/ijoe.v13i04.6962 \\ Lorella Gabriele \\ Università della Calabria, Arcavacata di Rende, Cosenza, Italy \\ lorella.gabrieledunical.it \\ Davide Marocco \\ Università degli Studi di Napoli Federico II, Napoli, Italy \\ davide.marocco@unina.it \\ Francesca Bertacchini \\ Università della Calabria, Arcavacata di Rende, Cosenza, Italy \\ francesca.bertacchini@unical.it \\ Pietro Pantano \\ Università della Calabria, Arcavacata di Rende, Cosenza, Italy \\ pietro.pantano@unical.it \\ Eleonora Bilotta \\ Università della Calabria, Arcavacata di Rende, Cosenza, Italy \\ eleonora.bilotta@unical.it
}

\begin{abstract}
The research aimed at presenting learning results on an Educational Robotics Lab carried out with university students that attended an Arts and Humanities Course Degree. In particular, cognitive abilities put into action by learners in using a Robotics Serious Game have been investigated and data has been collected by administering a pre and a post-test on motivation and using Project Based Learning (PBL) methodology. Significant results have been acquired on: (1) students' motivation in relation to their performance; (2) team work strategy, analyzing the PBL; and (3) learning results. Findings showed that "intrinsic motivation" of the participating students, gathered with a specific questionnaire, was high since the beginning of the Lab experience, corroborating the hypothesis that these cognitive activities are able to stimulate curiosity, interest, enjoyment and to foster the learning also in humanities careers.
\end{abstract}

Keywords-Educational Robotics, Cognitive processes in teaching/learning; Educational technologies; Constructivist approach. 


\section{Introduction}

In recent years, a growing body of research papers, in the realm of education, deal with Robotics experiences. This latter field also known as Educational Robotics foresees the use of commercial robotics kits as well as robotics simulation software (Serious Games), to allow students without specific knowledge in robotics or computer science, to design, build and program robotic artifacts or to evolve robots' behaviour. As Lund and Pagliarini [1] highlight, these activities enable students to develop advanced cognitive skills: problem solving [2], thinking strategies and the acquisition of new concepts. Educational robots belong to the "cognitive technologies family" [3], which are tools designed to be as "intellectual partners" for students able to engage and facilitate critical thinking and high-level cognitive processes [4], [5], [6], [7]. According to the constructivist and constructionist perspective [8], [9], [10], students' learning significantly improves when they are actively involved in the construction of meaning. This construction is more effective if it does not happens only at a mental level, but is supported by a "real" construction, such as handling hardware and software artefacts. Paraphrasing Papert [9], we might say that artefacts, both real - robots - and virtual - simulation software- are objects helping us to think. They are useful tools that help us to reproduce parts of the existing problems in the real world. However, different studies [11,12] highlighted the innovative aspects of Educational Robotics as a means able to promote the developing skills and to support the learning process.

The ambition of this study is to: engage students of an Arts and Humanities Course Degree in learning different Robotics concepts during an Educational Robotics Lab; to investigate the cognitive skills put into action by students in using the educational tools BrainFarm (a Serious Games based on robotics simulation), through a systematic methodology. By administering a pre and post-test on motivation and using a group Project Based Learning methodology, significant results have been acquired regarding: (1) the motivations of the students and how these motivations affect the final results; (2) the work strategies adopted by each group toward the solution of encountered problems; and (3) the learning results. Findings show that "intrinsic motivation" of students in learning robotics concept was high since the beginning of the experimentation, corroborating the hypothesis that these kind of activities stimulate curiosity, interest and enjoyment for the task itself.

The paper is organized as follows: Section 2 discusses the related work about the use of robotics in different educational contents. Section 3, the Method section, describes Aims, Participants, Materials, and Procedures adopted, as well as the data collection and analysis methodology; Section 4 reports the results; Section 5 contains Conclusions and Future work.

\section{Related work}

Educational Robotics is a research field that in a very short time acquired an important role at international level, stimulating the interest of different institutions, 
schools and universities, both from a didactic and a research point of view. Small robots or Robotics Serious Games are used in an educative contexts to create entertaining [13], joyfully and perceptive experiences to favour learning and understanding. A lot of research highlights how Educational Robotics represents a powerful tools that allow students to create an ideal bridge between their knowledge and the real-world phenomena. In fact, from a psychological point of view, designing and programming robots as well as simulating the robot's behaviour are complex activities that include hands-on and cognitive skills: (i) to design and to control the robot taking into account the characteristics of the world; (ii) autonomous robot experimentations, testing the control program of the robot behaviour; (iii) learning step by step the actions that the robot can run using the control program [14]. In the case of a simulation software (Serious Games) the robot is regarded as an autonomous artificial organism that develops its behaviour interacting with the environment. Hence, the focus shifts from the subject who analyses the problem from the outside of the robot and defines its behaviour, to the robot itself and its way of interacting with the environment. This latter aspects of robotics can be used to teach topics such as biology (environmental adaptation, evolutionism) and psychology, besides the obvious technological impact $[15,16,17]$. Numerous researches have been carried out in this realm that suggest how Educational Robotics comprises highly motivating activities that helps students in developing logical reasoning and problem solving, encouraging autoreflection, creativity [18], fostering collaboration and cooperation, as well as their acquisition and development of transversal skills and competences between different disciplines [19], [20], [21]. Schneider, Wildermuth, \& Wolf [22] discuss possible educational aspects of robotic competitions, as well as Bertacchini, Gabriele, Tavernise [23] and useful in promoting and facilitating learning and teaching. KärnäLin, Pihlainen-Bednarik, Sutinen \& Virnes [24], Valadão, Bastos, Bôrtole, Perim, Celino, Rodor, et al. [25] noticed how Lego tools encouraged students to try new things and to be creative, thus the observed strong motivation and enthusiasm can be partly a consequence of the charm of novelty. Focusing on the methods adopted in Educational Robotics researches, Buiu [26], combined simulation and experiments on real robots with remote experimentation strategy with the aim to integrate advanced educational technologies into the traditional curriculum. The author verified that the proposed methodology stimulates the acquisition, retention, reinforcement and refining of knowledge. Alimisis, Frangou \& Papanikolaou [27] adopted a constructivist methodology for training teachers in robotic technology within the framework of a teacher training course. The evaluation of the methodology is seen through questionnaires that the trainees filled in and the diary they kept. Correll, Wing \& Coleman [28] adopting a low cost methodology which combines simulation-based laboratory assignment with compatible hardware devices, they focused on performance-based assessment with an open-ended final project/competition and they evaluated both content learning and retention. In the same way, Riek [29] emphasizes that active, cooperative and problem-based learning relates with the good performance achieved by students registered in an educational robotics course. Eteokleous-Grigoriou \& Psomas [30], employing a case study methodology, examined whether robotics used within classroom activity enhances students' ability to apply the knowledge and skills 
gained across different subject topics. Moreover, they investigated the students' initial experiences, attitudes and opinions towards the integration of robotics as an educational tool. Yilmaz, Ozcelik, Yilmazer, Nekovei [31] verified the positive impact of the project-based robotics curriculum in stimulating student interest and how competition-driven environment can significantly improve student activities and creativity as well as [32] and [33]. As suggested by literature, the Robotics Laboratory adopted a constructivist approach and the project-based learning to collect data.

\section{$3 \quad$ Related work}

\subsection{Aims}

The purpose of this study is aimed to verify whether individuals' motivations affect the learning results of students with a humanistic background, engaged in experienced different Robotics concepts during an Educational Robotics Lab. A pre and post-test on motivation and the Project Based Learning methodology, allowed us to collect different data regarding: (1) the motivations of the students; (2) the work strategies adopted by each group toward the solution of encountered problems; and (3) the learning results.

\subsection{Participants}

The sample is composed by 136 students $(\mathrm{M}=8, \mathrm{~F}=128)$ enrolled at the first year of Cognitive Psychology at the Arts Faculty of the University of Calabria. The age of participants spans between 19 and 28 years (mean age 21.08). The $45 \%$ attended a Humanistic High School, 26\% attended a Scientific High School, 7\% attended a Technical High School, 23\% Professional High School.

\subsection{Procedure: Educational Robotics Laboratory organization}

Students attended the Educational Robotics Laboratory for six weeks, one two-hour meeting per week. All the activities were introduced using multimedia materials, adopting a participative and collaborative approach. Students were always invited to express their opinions and their doubts, stimulating their critical thinking and improving their learning. At the beginning of the Laboratory, after a brief presentation of the educational activities, researchers individually administered (2 hours): 1) an entry questionnaire to detect computer science knowledge of the students; 2) a motivation questionnaire [34] to understand if motivational features might affect the students' performance. The laboratory foreseen a theoretical and a hands-on stage. Theoretic stage ( 2 hours): researchers presented basic concepts of robotics regarding evolutionary robotics (e.g. neural networks, genetic algorithms, simulations, mutation, fitness function) and biology (e.g. natural selection, reproduction). At the same time, the BrainFarm software [35] (see section 3.4) has been introduced and explained. At the end of this phase, the subjects freely formed some workgroups and the researchers 
explained the tasks: each workgroup had "to train a robot able to move in an arena where are present boundary walls and an obstacle (a cylinder)" and to present a project at the end of the Laboratory. In the project, each group had to document the lab activities, specifying all the procedures that guided them in understanding and solving the assigned task (problem). Hands-on stage (simulation): during this stage (students have had 4 weeks to complete the assignment), students worked on the robot training and on the report. The students had to report the working methods adopted by the group in the planning the strategies adopted to solve the assigned task, and state which changes they made on each evolution run of the software. In the last meeting (1 hour) the motivation questionnaire [34] has been administered again. This second administration of the questionnaire was meant to evaluate any motivation changes in the students after the Lab.

\subsection{Materials}

The software used for the present research was BrainFarm: a serious game designed by [35] to introduce students in evolutionary robotics field. The software allows to design the architecture of robots' brains (artificial neural networks) and to control their behaviour by using a those neural networks with architectures of different complexity. In BrainFarm robots can be trained by means of genetic algorithms or learning algorithms. In a very easy e intuitive way, users have to: (1) choose one of the four types of robots available; (2) set the network parameters; (3) select the training modalities and the environment in which the robots will evolve. Finally, by loading a project file, users can train the network. The system will create a neural network that will have as input the robot's sensors reading. The output of the network will be translated into motors activations. The neural network can be downloaded and tested onto several real robots: Lego Next, Khepera and E-puck robots (see Figure 1).

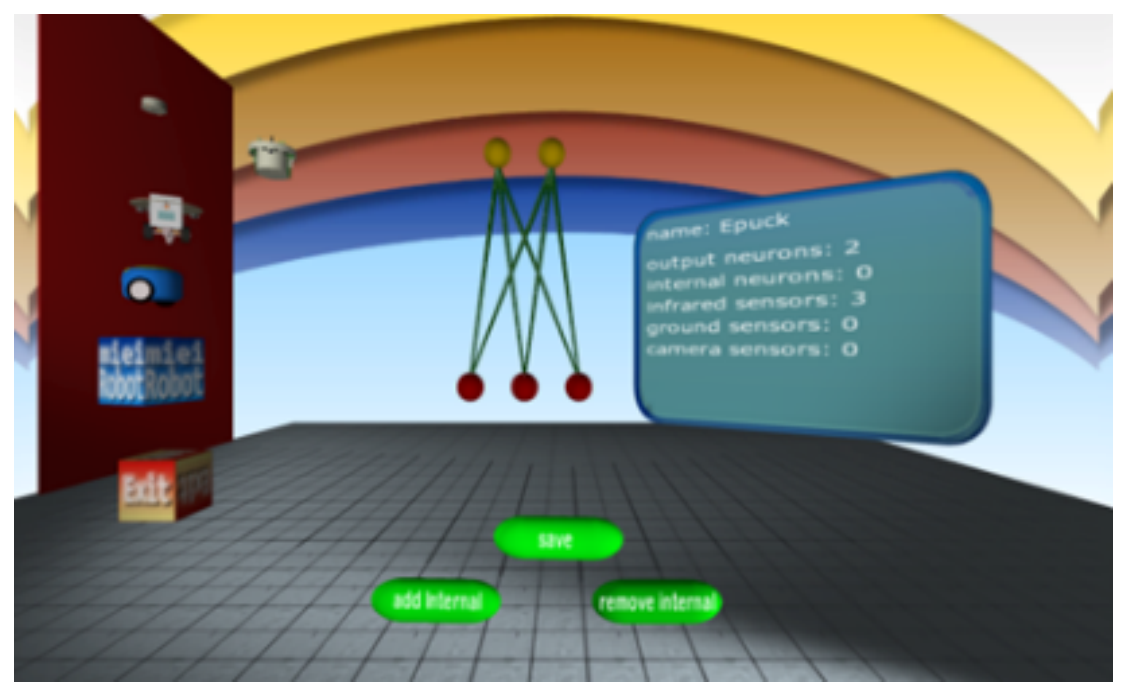

Fig. 1. A screenshot of BrainFarm software [35] 


\section{Data collection and Methods of analysis}

The entry questionnaire was made of six closed questions useful to collect some demographic data and to assess the level of computer science knowledge of the students. The questions were analysed from a quantitative point of view, calculating the frequencies for each answer and using SPSS ${ }^{\circ}$. The Science Motivation Questionnaire II [34] has been administered at the beginning (pre-test) of the research and at the end (post-test) to understand if motivational features (such as intrinsic motivation, selfdetermination, self-efficacy, career motivation, and grade motivation) might affect the students' performance. Moreover, to understand Working methods, Modalities of work subdivision inside the group and Cognitive strategies adopted by students in evolving the robot according to the task assignment, the report (Project Based Learning) [36] has been analysed according to Table 1 (a) and (b).

Table 1. Methodology of analysis of the Project Based Learning - PBL (a) and Report (PBL) assessment (b)

Methodology of analysis of the PBL
Working methods adopted
1. Workgroup: work carried out by a group of students
2. Individual: work carried out by a single person
Modalities of work subdivision inside the group
1. Cooperative: students negotiate the solution among
the group members
2. Collaborative: students ask suggestions to the
researcher-expert
Cognitive strategies adopted by students in evolving the
robot according to the task assignment
1. Solution focused strategy: modify of the evolution
parameters over and over again (also random
changes)
2. Problem focused strategy: analyzed in detail the
assigned task, taking into account the performance
that the robot had to do

(a)

\begin{tabular}{l} 
Report (PBL) assessment \\
VERY GOOD = The group evolved a robot controller taking \\
into account the assigned task. Every step of the robot \\
evolution has been detailed and explained, as well as the \\
problems incurred and the working modalities. Moreover, \\
students organized the report as a scientific paper, with a \\
detailed background, results represented with graphs to \\
show the results of each experiment and a graph to compare \\
the results of all robot performances. \\
\hline SUFFICIENT = The group evolved a robot controller taking \\
partially into account the assigned task. The environment \\
during the evolutionary processes was modified many times \\
and evolutionary parameters were changed almost \\
randomly. Students organized the report as a scientific \\
paper, with few comments accompanying the graphs. \\
\hline INSUFFICIENT = The group evolved a robot controller \\
without taking into account the assigned task.
\end{tabular}

(b)

\section{$5 \quad$ Results}

\subsection{Results of Entry Questionnaire}

By analysing the entry questionnaire, results show that $20 \%$ of participants use a PC to play videogames or for social networking purposes, $65 \%$ to surfing internet, $2 \%$ to programme and $13 \%$ as support to study. Only $11 \%$ have specific knowledge of computer science and are able to use a programming language. None has attended a Robotics course previously. 


\subsection{Results of Science Motivation Questionnaire}

Since the objective of the research is to investigate how motivation affect learning, the Science Motivation Questionnaire II [34] has been administered at the begin (pretest) and after the Robotics Lab (post-test). Cronbach alphas value has been calculated for the pre (.923) and the post-test motivation questionnaires (.934) and an excellent internal consistency for both tests emerged. We ran Mean and Standard Deviations on Pre and Post-Test Motivation questionnaire for each of the five following indicators (Table 2) Intrinsic Motivation, Career Motivation, Self Determination, Self-Efficacy, Grade Motivation. We have no meaningful gender differences, since a lower number of males $(n=8)$ composed the sample.

Table 2. Mean value obtained by students in Pre and Post-test M-Mean and Standard Deviations on Pre- Post Test Motivation questionnaire

\begin{tabular}{|c|c|c|c|c|c|c|}
\hline & \multicolumn{3}{|c|}{ Pre-test Motivation } & \multicolumn{3}{|c|}{ Post-test Motivation } \\
\hline & $\begin{array}{l}\text { Men } \\
(n=8)\end{array}$ & $\begin{array}{l}\text { Women } \\
(n=128)\end{array}$ & $\begin{array}{c}\text { Total } \\
(n=136)\end{array}$ & $\begin{array}{l}\text { Men } \\
(n=8)\end{array}$ & $\begin{array}{l}\text { Women } \\
(n=128)\end{array}$ & $\begin{array}{c}\text { Total } \\
(n=136)\end{array}$ \\
\hline \multicolumn{7}{|l|}{ Intrinsic Motivation } \\
\hline$M$ & 3,43 & 3,32 & 3,33 & 3,33 & 3,43 & 3,34 \\
\hline$s d$ & 0,34 & 0,30 & 0,30 & 0,76 & 0,27 & 0,30 \\
\hline \multicolumn{7}{|l|}{ Career Motivation } \\
\hline$M$ & 3,47 & 3,64 & 3,63 & 3,55 & 3,01 & 3,52 \\
\hline$s d$ & 0,72 & 0,36 & 0,38 & 0,40 & 0,25 & 0,40 \\
\hline \multicolumn{7}{|l|}{ Self Determination } \\
\hline$M$ & 3,40 & 3,33 & 3,33 & 3,51 & 3,68 & 3,52 \\
\hline sd & 0,53 & 0,35 & 0,36 & 0,38 & 0,38 & 0,38 \\
\hline \multicolumn{7}{|l|}{ Self-Efficacy } \\
\hline$M$ & 2,93 & 2,89 & 2,89 & 3,03 & 3,30 & 3,04 \\
\hline$s d$ & 0,40 & 0,31 & 0,32 & 0,32 & 0,22 & 0,32 \\
\hline \multicolumn{7}{|l|}{ Grade Motivation } \\
\hline$M$ & 3,83 & 3,58 & 3,60 & 3,66 & 3,25 & 3,64 \\
\hline sd & 0,37 & 0,39 & 0,38 & 0,40 & 0,40 & 0,40 \\
\hline
\end{tabular}

In particular, the Mean value shows a small increase with respect to the indicators Self Determination, Self-Efficacy and Grade Motivation. A Pearson product-moment correlations were carried out between Pre-test Motivation and Post-test Motivation: a statistical positive correlation has been recorded between Pre - and Post "SelfEfficacy" indicator ( $r=, 220 ; \mathrm{p}>0,05)$, however the value is too low to assume that a significate change has been produced by the laboratory activities. Moreover, at the end of the post-test motivation, students answered to open-ended questions on what they thought were the positive and negative aspects of the Robotics Lab. The answers have been mostly concise and among the positive aspects, $26 \%$ of the students underlined the workgroup experience, according the $50 \%$ of the students the Robotics topic were really interesting, as well as to observe robot's evolution (8\%), to use new soft- 
ware $(13 \%)$ and to discover the educational aspects of robotics. The same sample underlined the negative aspects of the Robotics Lab. $19 \%$ of the students judged the topic really complex, some students reported some difficulties regarding the project work (13\%), and the software usability (42\%). Finally, $26 \%$ of the students have experienced no negative aspects whatsoever.

\section{Results of Project- Based Learning}

Analyzing the project (PBL) developed by each workgroup, we obtained very interesting information. With regard to the "Working method adopted", students freely chose the modality. In particular, 132 students worked in group (17 groups were composed by 2 persons, 18 groups were composed by 3 persons, 7 groups by 4 persons, 2 groups by 5 persons, 1 group by 6 persons), 4 students worked individually.

As concerning the "Modalities of work subdivision" inside the group, two approach has been individuated: "Cooperative" and "Collaborative". 17 groups adopted a Cooperative approach, in which students divided equally the work among the members of the group. In case of problems, they discusses within the group "what to do" and "how to solve" them cooperatively and negotiated the solution accordingly. At the end of the workgroup, students all together assessed the robot performances and opted whether or not to run further experiments. They used online resources or the scientific papers given during the course to support the completion of the workgroup. The other 28 workgroups adopted a Collaborative approach, in which students organized and negotiated efforts in the group. Problems were generally discussed with the researcher-expert. At the end of the work, students all together assessed the robot performance. Also in this case, participants seek researcher-expert suggestions in order to decide whether or not to run further robot experiments. With regards to the students that worked individually, 3 of them asked several suggestions and explanations to the researcher-expert, while 1 of them ended the assigned task without asking further explanation and solving "through internet support" or "searching scientific papers" when problems occurred.

With respect to the Cognitive strategies adopted by students in evolving the robot according to the task assignment, we identified two main strategies: 1) Solution focused strategy: Based on modifications of the evolutionary parameters over and over again (trials and errors); 2) Problem focused strategy: Based on detailed analysis of the assigned task, taking into account the performance that the robot had to do.

As regards the "Report assessment" 24 groups and 1 single student, had a "VERY GOOD" mark, 18 groups and 2 single students had a "SUFFICIENT" mark, 3 groups and 1 single student had an "INSUFFICIENT" mark. We can remark that, among the students that had a "VERY GOOD" marks, the 70\% used a Problem focused strategy while $30 \%$ a Solution focused strategy, while as regards the "Modalities of work subdivision" all adopted a Cooperative approach. 


\section{Conclusions and Future Plans}

As the literature highlights (Section 1 and 2), the potentials of using robotics as an educational tool are really huge. However, according to Benitti [37], only a small number of researches applied a systematic methodology and standardized assessment tools, as well as low cost robotics tools. This paper adopted a systematic methodology for collect data on motivation, with the purpose to verify whether individuals' motivations affect the learning results of students with a humanistic background, engaged in experienced different Robotics concepts during an Educational Robotics Lab.

Concerning the motivation, a positive statistical correlation (Person product moment) has been recorded between Pre - and Post-test in the "Self-Efficacy" indicator, however the value is too low to assume that a significant change has been produced by the laboratory activities. Nevertheless, this latter indicator (self-efficacy) refers to the students' belief that students are firmly persuaded they can achieve good results in a "robotics lab". Hence, we could assume that students' motivation is already higher at the beginning of the Robotics Lab course (as "Intrinsic motivation" value show) and no significant change can be recorded. In fact, the Robotics Lab is not mandatory in the Psychology course, and students freely chosen to attend it. Interestingly, the same students, in the open-ended questions (post-test motivation questionnaire) assert that "these activities stimulate curiosity". For what concerns the proposed methodology, we think that the use of the Project Based Learning methodology allows the researcher to collect a great variety of data, since it engages students in exploring and investigating new concepts. Students do not feel to be evaluated and they feel free to write and express their opinions. However, we also asked them to supply some key information, such as the work modalities or to explain the different steps of the work. The learners that adopted a "solution focused" working strategy started by setting the robot's and evolutionary parameters without analyzing in detail the assigned task. Indeed, they modified the robot over and over again, as well as the environment and the evolution parameters, changing also the type of robot and its internal memory. This approach is characterized by random changes. They simply compared the mean fitness values of each experiment at the end of the experiments. Students proceeded in the work for trials and errors. Learners who adopted a "problem focused" working strategy analyzed in detail the task assigned. Then, as first step, they defined the environment according to the given task, and then they chose a specific robot for all the experiments. They set the evolution parameters, as "explained in the report" and they changed the parameters one-by-one in order to correlate the results obtained to the parameters setting. As stressed by the results, we observed that a higher percentage of the groups took advantage from cooperation, using the group to discuss and to solve problems.

Summing up, in this study emerged how these technologies can really support, lead and enhance user's thinking and cognitive processes, since they help students to use in a fruitful and effective way his/her mental efforts [32]. We could assert that Educational Robotics Software as well as Educational Robotics kits, belong to the great family of "cognitive artefacts": the first one allow to handle mental concepts, the second one allow learners to handle real objects, building mental meaning. 
However, the results of this study are limited to one group. Further experimentation are necessary with the inclusion of a control group in addition to the experimental one. In our opinion, it would be really interesting to verify how motivation changes the educational paradigm, administrating a pre and post-test both in a control group and in experimental one and how motivation affects learning results in both groups.

\section{$8 \quad$ References}

[1] Lund, H. H., \& Miglino, O., 1998. Evolving and Breeding Robots. Proceedings of first European Workshop on Evolutionary Robotics, Paris, pp. 200-204. https://doi.org/10.1007/3540-64957-3 73

[2] Faraco, G., \& Gabriele, L. (2007). Using LabVIEW for applying mathematical models in representing phenomena. Computers and Education, 49 (3), pp. 856-872. https://doi.org/10.1016/j.compedu.2005.11.025

[3] Salomon, G., Perkins, D. N., \& Globerson, T (1991). Partners in cognition: Extending human intelligence with intelligent technologies. Educational Researcher, 20, pp. 2-9. https://doi.org/10.3102/0013189X020003002

[4] Caci, B., D’Amico, A., \& Chiazzese, G. (2013). Robotics and Virtual Worlds: An experiential learning lab. In Biologically Inspired Cognitive Architectures 2012 (pp. 83-87). Springer Berlin Heidelberg. https://doi.org/10.1007/978-3-642-34274-5 19

[5] Gaudiello, I., \& Zibetti, E. (2016). Learning Robotics, with Robotics, by Robotics: Educational Robotics. John Wiley \& Sons. https://doi.org/10.1002/9781119335740

[6] Bilotta, E., Gabriele, L., Servidio, R. C., \& Tavernise, A. (2009a). Edutainment Robotics as Learning Tool. Lecture Notes in Computer Science (including subseries Lecture Notes in Artificial Intelligence and Lecture Notes in Bioinformatics), 5940 LNCS, 2009, pp. 2535, https://doi.org/10.1007/978-3-642-11245-4 3

[7] Bilotta, E., Gabriele, L., Servidio, R. C., \& Tavernise, A. (2009b). Edutainment robotics as learning tool. 4th International Conference on E-Learning and Games, Edutainment 2009; Banff, AB; Canada; 9 August 2009, 5670 LNCS, 2009, pp. 422. https://doi.org/10.1007/978-3-642-03364-3 50

[8] Piaget, J. (1967). Lo sviluppo mentale del bambino. Torino: Einaudi.

[9] Papert, S. (1991). Situating constructionism. In I. Harel \& S. Papert (Eds.), Constructionism (pp. 1-11). Norwood, NJ: Ablex Publishing.

[10] Gabriele, L., Tavernise, A., Bertacchini, F. (2012). Active learning in a robotics laboratory with university students. Cutting-Edge Technologies in Higher Education, 6 (PARTC), pp. 315-339. https://doi.org/10.1108/S2044-9968(2012)000006C014

[11] Ospennikova, E., Ershov, M., \& Iljin, I. (2015). Educational Robotics as an Inovative Educational Technology. Procedia-Social and Behavioral Sciences, 214, 18-26. https://doi.org/10.1016/j.sbspro.2015.11.588

[12] Tocháček, D., Lapeš, J., \& Fuglík, V. (2016). Developing technological knowledge and programming skills of secondary schools students through the educational robotics projects. Procedia-Social and Behavioral Sciences, 217, 377-381. https://doi.org/10.1016/ j.sbspro.2016.02.107

[13] Bertacchini F., Bilotta E., Pantano P. (in press). Shopping with a robotic companion, Computers in Human Behavior, https://doi.org/10.1016/j.chb.2017.02.064

[14] Martin, F. (2001). Interviste. In E. Bilotta (Ed.), In ONDE, Periodico di Comunicazione e Innovazione Tecnologica della DATEL, Quadrimestrale di approfondimento scientifico. Catanzaro: Abramo Editore. 
Paper-An Educational Robotics Lab to Investigate Cognitive Strategies and to Foster Learning in an...

[15] Abdechiri M., Faez K., Amindavar H., Bilotta E. (in press). The chaotic dynamics of highdimensional systems. Nonlinear Dynamics, 87, 2597-2610. https://doi.org/10.1007/ s11071-016-3213-3

[16] Bilotta E., Pantano, P., Vena, S. (in press). Speeding up cellular neural network processing ability by embodying memristors. IEEE Transactions on Neural Networks and Learning Systems. https://doi.org/10.1109/TNNLS.2015.2511818

[17] Lombardo M. C., Barresi R., Bilotta E., Gargano F., Pantano P., Sammartino M. (in press). Demyelination patterns in a mathematical model of multiple sclerosis. J. Math. Biol. https://doi.org/10.1007/s00285-016-1087-0

[18] Rodríguez, J. C. R., Martín-Pulido, E., Padrón, V. J., Alemán, J. A., García, C. R., \& Quesada-Arencibia, A. (2016, September). Ciberlandia: An Educational Robotics Program to Promote STEM Careers in Primary and Secondary Schools. In International Conference on Interactive Collaborative Learning (pp. 440-454). Springer, Cham.

[19] Sullivan, F. R. (2017). Creativity, Technology, and Learning: Theory for Classroom Practice. Routledge.

[20] Agatolio, F., Pivetti, M., Di Battista, S., Menegatti, E., \& Moro, M. (2016, November). A Training Course in Educational Robotics for Learning Support Teachers. In International Conference EduRobotics 2016 (pp. 43-57). Springer, Cham.

[21] Bers, M.U., Flannery, L., Kazakoff, E. R., \& Sullivan, A. (2014). Computational thinking and tinkering: Exploration of an early childhood robotics curriculum. Computers \& Education, 72, 145-157. https://doi.org/10.1016/j.compedu.2013.10.020

[22] Schneider, F. E., Wildermuth, D., \& Wolf, H. (2012). Professional Ground Robotic Competitions From an Educational Perspective A Consideration Using the Example of the European Land Robot Trial (ELROB), Intelligent Systems (IS), 2012 6th IEEE International Conference, Sofia, 6-8 Sept. 2012, pp. $399-405$.

[23] Bertacchini, F., Gabriele, L., Tavernise, A. (2011). Bridging educational technologies and school environment: Implementations and findings from research studies, Educational Theory, pp. 63-82.

[24] Kärnä-Lin, E., Pihlainen-Bednarik, K., Sutinen E., \& Virnes, M. (2006). Can Robots Teach? Advanced Learning Technologies, 2006. Sixth International Conference on, pp.319,321, 5-7 July 2006

[25] Valadão, C., Bastos, T.F., Bôrtole, M., Perim, V., Celino, D., Rodor, F., Gonçalves, A., \& Ferasoli, H. (2011). Educational Robotics as a Learning Aid for Disabled Children. Biosignals and Biorobotics Conference (BRC), Jan. 2011, pp. 6-8. https://doi.org/10.1109/ brc. 2011.5740667

[26] Buiu, C. (2008). Hybrid Educational Strategy for a Laboratory Course on Cognitive Robotics, IEEE TRANSACTIONS ON EDUCATION, 51(1), $100-107$. https://doi.org/10.1109/TE.2007.906605

[27] Alimisis, D. Frangou, S. Papanikolaou K. (2009). A Constructivist Methodology for Teacher Training in Educational Robotics: the TERECoP Course in Greece through Trainees' Eyes. Advanced Learning Technologies, 2009. ICALT 2009. Ninth IEEE International Conference on, pp.24-28, 15-17 July 2009, https://doi.org/10.1109/ICALT.2009.86

[28] Correll, N., Wing, R., Coleman, D. (2013). A One-Year Introductory Robotics Curriculum for Computer Science Upperclassmen. IEEE TRANSACTIONS ON EDUCATION, 56 (1), 54 - 60. https://doi.org/10.1109/TE.2012.2220774

[29] Riek, L. D. (2013). Embodied Computation: An Active-Learning Approach to Mobile Robotics Education. IEEE TRANSACTIONS ON EDUCATION, 56 (1), 67 - 72. https://doi.org/10.1109/TE.2012.2221716 
[30] Eteokleous-Grigoriou, N., \& Psomas, C. (2013). Integrating Robotics as an Interdisciplinary-Educational Tool in Primary Education. In R. McBride \& M. Searson (Eds.), Proceedings of Society for Information Technology \& Teacher Education International Conference 2013 (pp. 3877-3881). Chesapeake, VA: AACE.

[31] Yilmaz, M., Ozcelik, S., Yilmazer, N., \& Nekovei, R. (2013). Design-Oriented Enhanced Robotics Curriculum, IEEE TRANSACTIONS ON EDUCATION, 56 (1), 137-144.

[32] Gabriele, L., \& Bilotta E. (2013). ROBOT FOR THINKING: COGNITIVE STRATEGIES TO EXPERIMENT THE USE OF EDUCATIONAL ROBOTICS IN CLASSROOM, EDULEARN13 Proceedings, pp. 5801-5810.

[33] Bertacchini F., Bilotta E., Gabriele L., Servidio R., 2010. USING LEGO MINDSTORMS IN HIGHER EDUCATION: Cognitive strategies in programming a quadruped robot, The 18th International Conference on Computers in Education, ICCE 2010, November 29, 2010 (Monday) to December 3, 2010 (Friday) Putrajaya, Malaysia.

[34] Glynn, S. M., Brickman, P., Armstrong, N., \& Taasoobshirazi, G. (2011). Science Motivation Questionnaire II: Validation with science majors and nonscience majors. Journal of Research in Science Teaching, 48, 1159-1176. https://doi.org/10.1002/tea.20442

[35] Gigliotta, O. Petrosino, G., Schembri, M. (2011). BrainFarm: Cervelli robotici a portata di mouse. Atti dell'ottavo Convegno Nazionale Associazione Italiana di Scienze Cognitive, AISC'11 (edited by), Rubinacci, F. Rega, A., Lettieri, N., Milano 1-2 dicembre 2011.

[36] Chu, S. K. W., Tse, S. K., \& Chow, K. (2011). Using collaborative teaching and inquiry project based learning to help primary school students develop information literacy and information skills. Library \& Information Science Research, 33(2), 132-143. https://doi.org/10.1016/j.lisr.2010.07.017

[37] Benitti, B. F. V., (2012). Exploring the educational potential of robotics in schools: a systematic review. Computers \& Education, 58(3), 978-988 https://doi.org/10.1016/j.comp edu.2011.10.006

\section{Authors}

Lorella Gabriele is with the Physics Department, University of Calabria, Rende, Italy. She is a post-doc Fellow and is interested in the following topics: psychology of programming, educational technologies and their use in didactic context, learning, techniques of Human Computer Interaction, communications systems and their use for educational purposes. She is an occasional referee of the journals Computers \& Education, Scientific Research and Essays, and member of the Editorial Board of the Journal of Applied Research in Higher Education (JARHE). She worked in different national and international projects (lorella.gabriele@unical.it).

Davide Marocco received his $\mathrm{PhD}$ in Artificial Intelligence at the University of Calabria, Italy, in 2004. He is currently Associate Professor in Psychometric at the University of Naples Federico II. He was previously Reader on Cognitive Robotics and Intelligent Systems at the University of Plymouth, UK. His research interests are focused on alternative assessment of human and artificial systems performances, cognitive robotics and evolutionary robotics models of behavior (e-mail: davide.marocco@unina.it).

Francesca Bertacchini is with the Mechanical, Energy and Management Engineering Department, University of Calabria, Rende, Italy. She is a Ph.D in "Psychology of Programming and Artificial Intelligence", and a Post-Doc Fellow. She is a 
Paper-An Educational Robotics Lab to Investigate Cognitive Strategies and to Foster Learning in an...

member of the research group ESG (http://galileo.cincom.unical.it/), and works in the Laboratory of Psychology and Cognitive Science at University of Calabria, designing educational-entertaining environments for science communication and education. Among her research interests we can cite the followings: Educational Technologies, Art \& Science, Scientific Visualization, Psychology of Music (francescabertacchini@live.it).

Pietro Pantano is with the Physics Department, University of Calabria, Rende, Italy. He is a full Professor of Physics and Mathematics at University of Calabria. His main research interests concern several topics according to an interdisciplinary approach, among which we can cite the followings: e-Learning systems; Scientific communication; Artificial life. He is a member of several national and international scientific communities, scientific committees and organized several congresses and workshops. From 2011 is the director of a Doctoral School at University of Calabria. He participated in national and international projects as responsible of local research unit as well as international coordinator (pietro.pantano@unical.it).

Eleonora Bilotta is with the Physics Department, University of Calabria, Rende, Italy. She is a full professor of General Psychology at University of Calabria, Italy, where she is also the director of the Cognitive Psychology Laboratory. Her research interests concern various scientific topics from an interdisciplinary point of view and comprise the following areas: Human Computer Interaction, Psychology of Programming, Information and communication technologies, Educational Technologies. She published more than 200 scientific papers and is the author of various books. She was the coordinator of (or participated in) national and international projects. Moreover, she is a member of several national and international scientific communities (eleonora.bilotta@unical.it).

Article submitted 30 March 2017. Published as resubmitted by the authors 05 May 2017. 